\title{
UKURAN ENTROPI BARU PADA HIMPUNAN KABUR INTUISIONISTIK BERNILAI INTERVAL
}

\author{
REZKY ATHARI NOVRITA, NOVA NOLIZA BAKAR \\ Program Studi S1 Matematika, \\ Fakultas Matematika dan Ilmu Pengetahuan Alam, Universitas Andalas, \\ Kampus UNAND Limau Manis Padang, Indonesia, \\ email: Rezkyathari@yahoo.co.id
}

Diterima 9 Maret 2019 Direvisi 7 April 2019 Dipublikasikan 7 Mei 2019

\begin{abstract}
Abstrak. Dalam kehidupan nyata banyak sekali kasus yang mengandung unsur ketidakpastian atau ketidakjelasan. Oleh karena itu, masalah ketidakpastian ini dapat diselesaikan dengan teori himpunan kabur (fuzzy set/FS). Teori himpunan kabur telah diperkenalkan oleh Dr. L.A Zadeh pada tahun 1965, kemudian beberapa bentuk umum telah diusulkan dan dipelajari untuk mengatasi ketidakjelasan. Atanassov mengusulkan konsep himpunan kabur intuisionistik (intuitionistic fuzzy set/IFS) dan himpunan kabur intuisionistik bernilai interval (interval value intuitionistic fuzzy set/IVIFS) sebagai dua topik penting dalam teori himpunan kabur. Salah satu topik kajian di himpunan kabur adalah ukuran entropi. Entropi dari himpunan kabur menggambarkan tingkat ke-kaburan atau ketidakjelasan dari himpunan kabur. Pada tulisan ini akan diusulkan ukuran entropi baru untuk himpunan kabur intuisionistik bernilai interval, serta bagaimana perbedaan antara ukuran entropi baru tersebut dengan beberapa ukuran entropi IVIFS yang pernah diusulkan sebelumnya.
\end{abstract}

Kata Kunci: Himpunan kabur, Himpunan kabur intuisionistik, Himpunan kabur bernilai interval, Himpunan kabur intuisionistik bernilai interval, Ukuran entropi

\section{Pendahuluan}

Salah satu topik kajian di himpunan kabur adalah ukuran entropi pada himpunan kabur intuisionistik bernilai interval. Ukuran entropi pada himpunan kabur intuisionistik bernilai interval (IVIFS) digunakan untuk menggmbarkan tingkat kekaburan dari suatu IVIFS.

Untuk pengukuran entropi IVIFS, Vlachos dan Sergiadis [7] mengungkapkan hubungan intuitif dan matematis antara gagasan entropi untuk FS dan IFS dalam hal ketidakjelasan dan intuisi. Mereka menunjukkan bahwa entropi untuk FS memang merupakan ukuran ketidakjelasan, sedangkan untuk IFS, entropi dapat mengukur ketidakjelasan dan intuisi. Ketidakjelasan didominasi oleh selisih antara derajat keanggotaan dan derajat ketidakanggotaan, dan intuisi didominasi oleh derajat keragu-raguan. Oleh karena itu, pada penelitian kali ini akan diperluas konsep ukuran entropi IFS pada IVIFS dengan mendefinisikan sebuah fungsi bernilai rill pada koleksi dari semua himpunan kabur intuisionistik bernilai interval sedemikian 
sehingga fungsi tersebut merupakan suatu ukuran entropi baru untuk IVIFS, serta bagaimana perbedaan antara ukuran entropi baru untuk IVIFS tersebut dengan ukuran entropi yang didefinisikan oleh Ye [10].

\section{Landasan Teori}

Misalkan X adalah suatu himpunan semesta.

\subsection{Himpunan Kabur Intuitionistik}

Definisi 2.1. [1] Suatu himpunan kabur intuisionistik (IFS) A atas X didefinisikan sebagai

$$
A=\left\{\left(x, u_{A}(x), v_{A}(x)\right) \mid x \in X\right\},
$$

dimana $u_{A}: X \rightarrow[0,1]$ dan $v_{A}: X \rightarrow[0,1]$, sehingga $u_{A}(x)$ disebut derajat keanggotaan atas $x \in X$ pada himpunan $A$ dan $v_{A}(x)$ disebut derajat ketidakanggotaan atas $x \in X$ pada himpunan A, dan untuk setiap $x \in X$ harus memenuhi $0 \leqslant u_{A}(x)+v_{A}(x) \leqslant 1$.

Selanjutnya Atanassov [1] juga menjelaskan bahwa jika dimisalkan

$$
\pi_{A}(x)=1-u_{A}(x)-v_{A}(x),
$$

maka $\pi_{A}(x)$ disebut derajat keragu-raguan keanggotaan atas $x \in X$ pada himpunan kabur intuisionistik $A$.

Definisi 2.2. [1] Untuk dua IFS $A=\left\{\left(x, u_{A}(x), v_{A}(x)\right) \mid x \in X\right\}$ dan $B=$ $\left\{\left(x, u_{B}(x), v_{B}(x)\right) \mid x \in X\right\}$, didefinisikan hubungan dan operasinya sebagai berikut:

(1) $A \subseteq B$ jika dan hanya jika $u_{A}(x) \leqslant u_{B}(x)$ dan $v_{A}(x) \geqslant v_{B}(x)$, untuk setiap $x \in X$

(2) $A=B$ jika dan hanya jika $A \subseteq B$ dan $B \subseteq A$, artinya $A=B$ jika dan hanya jika $u_{A}(x)=u_{B}(x)$ dan $v_{A}(x)=v_{B}(x)$;

(3) $A^{c}=\left\{\left(x, v_{A}(x), u_{A}(x)\right) \mid x \in X\right\}$;

(4) $A \cap B=\left\{\left(x, \min \left\{u_{A}(x), u_{B}(x)\right\}, \max \left\{\left(v_{A}(x), v_{B}(x)\right\}\right) \mid x \in X\right\}\right.$;

(5) $A \cup B=\left\{\left(x, \max \left\{u_{A}(x), u_{B}(x)\right\}, \min \left\{v_{A}(x), v_{B}(x)\right\}\right) \mid x \in X\right\}$.

\subsection{Himpunan Kabur Intuisionistik Bernilai Interval}

Definisi 2.3. Misalkan int $(0,1)$ adalah himpunan dari semua subinterval tertutup dari interval $[0,1]$. Suatu himpunan kabur intuisionistik bernilai interval (IVIFS) $A$ atas $X$ didefinisikan sebagai

$$
A=\left\{\left(x, u_{A}(x), v_{A}(x)\right) \mid x \in X\right\},
$$

dimana $u_{A}: X \rightarrow \operatorname{int}(0,1)$ dan $v_{A}: X \rightarrow \operatorname{int}(0,1)$, sehingga $u_{A}(x)$ disebut derajat keanggotaan atas $x \in X$ pada himpunan $A$ dan $v_{A}(x)$ disebut derajat ketidakanggotaan atas $x \in X$ pada himpunan $A$, dan untuk setiap $x \in X$ harus memenuhi $0 \leqslant \sup \left(u_{A}(x)\right)+\sup \left(v_{A}(x)\right) \leqslant 1$. 
Jika dimisalkan $u_{A}(x)=\left[u_{A}^{-}(x), u_{A}^{+}(x)\right]$ dan $v_{A}(x)=\left[v_{A}^{-}(x), v_{A}^{+}(x)\right]$, dengan $u_{A}^{-}(x)$ dan $u_{A}^{+}(x)$ masing-masing menyatakan infimum dan supremum dari $u_{A}(x)$, begitu juga dengan $v_{A}^{-}(x)$ dan $v_{A}^{+}(x)$, masing-masing menunjukkan infimum dan supremum dari $v_{A}(x)$, sehingga

$$
A=\left\{\left(x,\left[u_{A}^{-}(x), u_{A}^{+}(x)\right],\left[v_{A}^{-}(x), v_{A}^{+}(x)\right]\right) \mid x \in X\right\} .
$$

Selanjutnya jika dimisalkan

$$
\begin{aligned}
\pi_{A}(x) & =\left[\pi_{A}^{-}(x), \pi_{A}^{+}(x)\right], \\
& =\left[1-u_{A}^{+}(x)-u_{A}^{+}(x), 1-v_{A}^{-}(x)-v_{A}^{-}(x)\right],
\end{aligned}
$$

maka $\pi_{A}(x)$ disebut derajat keragu-raguan keanggotaan atas $x \in X$ pada himpunan kabur intuisionistik bernilai interval $A$.

Definisi 2.4. [2] Misalkan IVIFS(X) adalah himpunan dari semua himpunan kabur intuisionistik bernilai interval atas $X$. Untuk suatu $A, B \in$ $\operatorname{IVIFS}(X)$, dengan $A=\left\{\left(x,\left[u_{A}^{-}(x), u_{A}^{+}(x)\right],\left[v_{A}^{-}(x), v_{A}^{+}(x)\right]\right) \mid x \in X\right\}$ dan $B=$ $\left\{\left(x,\left[u_{B}^{-}(x), u_{B}^{+}(x)\right],\left[v_{B}^{-}(x), v_{B}^{+}(x)\right]\right) \mid x \in X\right\}$, didefinisikan hubungan dan operasinya sebagai berikut.

(1) $A \subseteq B$ jika dan hanya jika $\left[u_{A}^{-}(x), u_{A}^{+}(x)\right] \leqslant\left[u_{B}^{-}(x), u_{B}^{+}(x)\right]$ dan $\left[v_{A}^{-}(x)\right.$, $\left.v_{A}^{+}(x)\right] \geqslant\left[v_{B}^{-}(x), v_{B}^{+}(x)\right]$, untuk setiap $x \in X$

(2) $A=B$ jika dan hanya jika $A \subseteq B$ dan $B \subseteq A$, artinya $A=B$ jika dan hanya jika $u_{A}^{-}(x)=u_{B}^{-}(x), u_{A}^{+}(x)=u_{B}^{+}(x)$ dan $v_{A}^{-}(x)=v_{B}^{-}(x), v_{A}^{+}(x)=v_{B}^{+}(x) ;$

(3) $A^{c}=\left\{\left(x,\left[v_{A}^{-}(x), v_{A}^{+}(x)\right],\left[u_{A}^{-}(x), u_{A}^{+}(x)\right]\right) \mid x \in X\right\}$;

(4) $A \cap B=\left\{\left(x,\left[\min \left\{u_{A}^{-}(x), u_{B}^{-}(x)\right\}, \min \left\{u_{A}^{+}(x), u_{B}^{+}(x)\right\}\right],\left[\max \left\{v_{A}^{-}(x), v_{B}^{-}(x)\right\}\right.\right.\right.$ , $\left.\left.\max \left\{\left(v_{A}^{+}(x), v_{B}^{+}(x)\right\}\right]\right) \mid x \in X\right\}$

(5) $A \cup B=\left\{\left(x,\left[\max \left\{u_{A}^{-}(x), u_{B}^{-}(x)\right\}, \max \left\{u_{A}^{+}(x), u_{B}^{+}(x)\right\}\right],\left[\min \left\{v_{A}^{-}(x), v_{B}^{-}(x)\right\}\right.\right.\right.$ , $\left.\left.\left.\min \left\{v_{A}^{+}(x), v_{B}^{+}(x)\right\}\right]\right) \mid x \in X\right\}$.

Definisi 2.5. [3] Misalkan int $(0,1)$ menunjukkan himpunan dari semua subinterval tertutup dari interval $[0,1]$. Untuk $\left[a_{1}, b_{1}\right],\left[a_{2}, b_{2}\right] \in$ int $(0,1)$, didefinisikan sebagai berikut.

(1) $\left[a_{1}, b_{1}\right] \leqslant\left[a_{2}, b_{2}\right]$ jika dan hanya jika $a_{1} \leqslant a_{2}, b_{1} \leqslant b_{2}$;

(2) $\left[a_{1}, b_{1}\right] \preceq\left[a_{2}, b_{2}\right]$ jika dan hanya jika $a_{1} \leqslant a_{2}, b_{1} \geqslant b_{2}$;

(3) $\left[a_{1}, b_{1}\right]=\left[a_{2}, b_{2}\right]$ jika dan hanya jika $a_{1}=a_{2}, b_{1}=b_{2}$.

Definisi 2.6. [9] Misalkan $a=\left[a^{-}, a^{+}\right]$dan $b=\left[b^{-}, b^{+}\right]$, maka nilai kemungkinan dari $a \geqslant b$ didefinisikan sebagai:

$$
p(a \geqslant b)=\max \left\{1-\max \left\{\frac{b^{+}-a^{-}}{l_{a}+l_{b}}, 0\right\}, 0\right\},
$$

dimana $l_{a}=a^{+}-a^{-}$dan $l_{b}=b^{+}-b^{-}$.

Dengan cara yang sama, nilai kemungkinan dari $b \geqslant a$ didefinisikan sebagai:

$$
p(b \geqslant a)=\max \left\{1-\max \left\{\frac{a^{+}-b^{-}}{l_{a}+l_{b}}, 0\right\}, 0\right\} .
$$

Definisi di atas digunakan untuk membandingkan dua bilangan interval dan untuk menentukan peringkatnya. 


\subsection{Ukuran Entropi Himpunan Kabur Intuisionistik}

Menurut De Luca dan Termini [5] ukuran tingkat ketidakjelasan atau kekaburan disebut ukuran entropi.

Definisi 2.7. [6] Misalkan IFS $(X)$ adalah himpunan dari semua himpunan kabur intuisionistik atas $X$, dan $A=\left\{\left(x, u_{A}(x), v_{A}(x)\right) \mid x \in X\right\}$ adalah suatu himpunan kabur intuisionistik atas $X$. Sebuah fungsi $E: I F S(X) \rightarrow[0,1]$ disebut ukuran entropi pada $\operatorname{IFS}(X)$, jika E memenuhi sifat berikut:

(1) $E(A)=0$ jika dan hanya jika $A$ adalah suatu himpunan tegas (crisp set);

(2) $E(A)=1$ jika dan hanya jika $u_{A}(x)=v_{A}(x)$, untuk setiap $x \in X$;

(3) $E(A)=E\left(A^{c}\right)$ ( $A^{c}$ adalah komplemen dari $\left.A\right)$;

(4) $E(A) \leqslant E(B)$ (A lebih tegas atau kurang kabur dari $B$ ) jika $u_{A}(x) \geqslant u_{B}(x)$ dan $v_{B}(x) \geqslant v_{A}(x)$ untuk $u_{B}(x) \geqslant v_{B}(x)$ atau $u_{A}(x) \leqslant u_{B}(x)$ dan $v_{B}(x) \leqslant v_{A}(x)$ untuk $u_{B}(x) \leqslant v_{B}(x)$, untuk setiap $x \in X$.

\section{Pembahasan}

Sebelumnya, diasumsikan bahwa $X$ adalah suatu himpunan berhingga, dengan $X=$ $\left\{x_{1}, x_{2}, x_{3}, \cdots, x_{n}\right\}$ dan $n$ adalah banyaknya elemen pada $X$. Himpunan $\operatorname{IVIFS}(\mathrm{X})$ adalah himpunan dari semua himpunan kabur intuisionistik bernilai interval atas $\mathrm{X}$.

\subsection{Sebuah Ukuran Entropi Baru Pada IVIFS}

Wei dan Zhang [8] memperluas aksioma dari Szmidt dan Kacprzyk [6] untuk ukuran entropi IVIFS dengan mendefinisikan suatu ukuran entropi baru yang dinotasikan dengan $E(A)[8]$ untuk IVIFS.

Definisi 3.1. [4] Suatu IVIFS(X) adalah himpunan dari semua himpunan kabur intuisionistik bernilai interval atas $X$ dan $A \in I V I F S(X)$. Sebuah fungsi bernilai riil E: $\operatorname{IVIFS}(X) \rightarrow[0,1]$ disebut ukuran entropi pada suatu $\operatorname{IVIFS}(X)$, jika $E$ memenuhi syarat berikut:

(1) $E(A)=0$ jika dan hanya jika $A$ adalah suatu himpunan tegas (crisp set), yaitu $u_{A}^{-}\left(x_{i}\right)=u_{A}^{+}\left(x_{i}\right)=1$ dan $v_{A}^{-}\left(x_{i}\right)=v_{A}^{+}\left(x_{i}\right)=0$ atau $u_{A}^{-}\left(x_{i}\right)=u_{A}^{+}\left(x_{i}\right)=0$ dan $v_{A}^{-}\left(x_{i}\right)=v_{A}^{+}\left(x_{i}\right)=1$ untuk setiap $x_{i} \in X$;

(2) $E(A)=1$ jika dan hanya jika $\left[u_{A}^{-}\left(x_{i}\right), u_{A}^{+}\left(x_{i}\right)\right]=\left[v_{A}^{-}\left(x_{i}\right), v_{A}^{+}\left(x_{i}\right)\right]$, untuk setiap $x_{i} \in X$

(3) $E(A)=E\left(A^{c}\right)\left(A^{c}\right.$ adalah komplemen dari $\left.A\right)$;

(4) $E(A) \leqslant E(B)$ (A lebih tegas atau kurang kabur dari B) jika: $\left[u_{A}^{-}\left(x_{i}\right), u_{A}^{+}\left(x_{i}\right)\right] \leqslant\left[u_{B}^{-}\left(x_{i}\right), u_{B}^{+}\left(x_{i}\right)\right] \operatorname{dan}\left[v_{A}^{-}\left(x_{i}\right), v_{A}^{+}\left(x_{i}\right)\right] \geqslant\left[v_{B}^{-}\left(x_{i}\right), v_{B}^{+}\left(x_{i}\right)\right]$ untuk $\left[u_{B}^{-}\left(x_{i}\right), u_{B}^{+}\left(x_{i}\right)\right] \leqslant\left[v_{B}^{-}\left(x_{i}\right), v_{B}^{+}\left(x_{i}\right)\right]$

atau

$\left[u_{A}^{-}\left(x_{i}\right), u_{A}^{+}\left(x_{i}\right)\right] \geqslant\left[u_{B}^{-}\left(x_{i}\right), u_{B}^{+}\left(x_{i}\right)\right] \operatorname{dan}\left[v_{A}^{-}\left(x_{i}\right), v_{A}^{+}\left(x_{i}\right)\right] \leqslant\left[v_{B}^{-}\left(x_{i}\right), v_{B}^{+}\left(x_{i}\right)\right]$ untuk $\left[u_{B}^{-}\left(x_{i}\right), u_{B}^{+}\left(x_{i}\right)\right] \geqslant\left[v_{B}^{-}\left(x_{i}\right), v_{B}^{+}\left(x_{i}\right)\right]$

atau 
$\left[u_{A}^{-}\left(x_{i}\right), u_{A}^{+}\left(x_{i}\right)\right] \preceq\left[u_{B}^{-}\left(x_{i}\right), u_{B}^{+}\left(x_{i}\right)\right] \operatorname{dan}\left[v_{A}^{-}\left(x_{i}\right), v_{A}^{+}\left(x_{i}\right)\right] \succeq\left[v_{B}^{-}\left(x_{i}\right), v_{B}^{+}\left(x_{i}\right)\right]$ untuk $\left[u_{B}^{-}\left(x_{i}\right), u_{B}^{+}\left(x_{i}\right)\right] \preceq\left[v_{B}^{-}\left(x_{i}\right), v_{B}^{+}\left(x_{i}\right)\right]$

atau

$\left[u_{A}^{-}\left(x_{i}\right), u_{A}^{+}\left(x_{i}\right)\right] \succeq\left[u_{B}^{-}\left(x_{i}\right), u_{B}^{+}\left(x_{i}\right)\right] \operatorname{dan}\left[v_{A}^{-}\left(x_{i}\right), v_{A}^{+}\left(x_{i}\right)\right] \preceq\left[v_{B}^{-}\left(x_{i}\right), v_{B}^{+}\left(x_{i}\right)\right]$ untuk $\left[u_{B}^{-}\left(x_{i}\right), u_{B}^{+}\left(x_{i}\right)\right] \succeq\left[v_{B}^{-}\left(x_{i}\right), v_{B}^{+}\left(x_{i}\right)\right]$

untuk setiap $x_{i} \in X$.

Teorema 3.2. [8] Himpunan IVIFS $(X)$ adalah himpunan dari semua himpunan kabur intui-sionistik bernilai interval atas $X$, dan $A \in I V I F S(X)$. Sebuah fungsi $E(A)$ yang didefinisikan sebagai

$$
E(A)=\frac{1}{n} \sum_{i=1}^{n} \cos \frac{\left|u_{A}^{-}\left(x_{i}\right)-v_{A}^{-}\left(x_{i}\right)\right|+\left|u_{A}^{+}\left(x_{i}\right)-v_{A}^{+}\left(x_{i}\right)\right|}{2\left(2+\pi_{A}^{+}\left(x_{i}\right)+\pi_{A}^{-}\left(x_{i}\right)\right)} \pi
$$

adalah suatu ukuran entropi untuk IVIFS.

Teorema 3.3. [8] Fungsi genap $f:[-1,1] \rightarrow[0,1]$ monoton turun pada $[0,1], f(-1)=f(1)=0, f(0)=1$, dan $A \in I V I F S(X)$. Sebuah fungsi $E_{f}(A)$ yang didefinisikan sebagai,

$$
E_{f}(A)=\frac{1}{n} \sum_{i}^{n} f\left(\frac{\left|u_{A}^{-}\left(x_{i}\right)-v_{A}^{-}\left(x_{i}\right)\right|+\left|u_{A}^{+}\left(x_{i}\right)-v_{A}^{+}\left(x_{i}\right)\right|}{\left(2+\pi_{A}^{+}\left(x_{i}\right)+\pi_{A}^{-}\left(x_{i}\right)\right)}\right)
$$

adalah suatu ukuran entropi untuk IVIFS.

\subsection{Perbandingan Beberapa Ukuran Entropi}

Untuk $A \in I V I F S(X)$, Ye [10] mengusulkan dua ukuran entropi $L_{1}(A)$ dan $L_{2}(A)$ yaitu:

$$
\begin{aligned}
L_{1}(A)= & \frac{1}{n} \sum_{i=1}^{n}\left(\left[\sin \frac{1+u_{A}^{-}\left(x_{i}\right)+p W_{u}\left(x_{i}\right)-v_{A}^{-}\left(x_{i}\right)-q W_{v}\left(x_{i}\right)}{4} \pi\right.\right. \\
& \left.\left.+\sin \frac{1-u_{A}^{-}\left(x_{i}\right)-p W_{u}\left(x_{i}\right)+v_{A}^{-}\left(x_{i}\right)+q W_{v}\left(x_{i}\right)}{4} \pi-1\right] \frac{1}{\sqrt{2}-1}\right) \\
L_{2}(A)= & \frac{1}{n} \sum_{i=1}^{n}\left(\left[\cos \frac{1+u_{A}^{-}\left(x_{i}\right)+p W_{u}\left(x_{i}\right)-v_{A}^{-}\left(x_{i}\right)-q W_{v}\left(x_{i}\right)}{4} \pi\right.\right. \\
& \left.\left.+\cos \frac{1-u_{A}^{-}\left(x_{i}\right)-p W_{u}\left(x_{i}\right)+v_{A}^{-}\left(x_{i}\right)+q W_{v}\left(x_{i}\right)}{4} \pi-1\right] \frac{1}{\sqrt{2}-1}\right)
\end{aligned}
$$

dimana $W_{u}\left(x_{i}\right)=u_{A}^{+}\left(x_{i}\right)-u_{A}^{-}\left(x_{i}\right), W_{v}\left(x_{i}\right)=v_{A}^{+}\left(x_{i}\right)-v_{A}^{-}\left(x_{i}\right)$ dan untuk suatu $p, q \in[0,1]$.

Teorema berikut menunjukkan persamaan (3.3) dan persamaan (3.4) adalah sama. 
Teorema 3.4. [8] Himpunan IVIFS $(X)$ adalah himpunan dari semua himpunan kabur intuisionistik bernilai interval atas $X$. Untuk suatu $A \in I V I F S(X)$, misalkan

$$
L(A)=\frac{1}{n} \sum_{i=1}^{n}\left(\left[\sqrt{2} \cos \frac{u_{A}^{-}\left(x_{i}\right)+p W_{u}\left(x_{i}\right)-v_{A}^{-}\left(x_{i}\right)-q W_{v}\left(x_{i}\right)}{4} \pi-1\right] \frac{1}{\sqrt{2}-1}\right)
$$

dimana $W_{u}\left(x_{i}\right)=u_{A}^{+}\left(x_{i}\right)-u_{A}^{-}\left(x_{i}\right), W_{v}\left(x_{i}\right)=v_{A}^{+}\left(x_{i}\right)-v_{A}^{-}\left(x_{i}\right)$ dan untuk suatu $p, q \in[0,1]$. Maka $L_{1}(A)=L_{2}(A)=L(A)$.

\section{Kesimpulan}

Dari pembahasan dapat disimpulkan bahwa :

(1) Ukuran entropi pada himpunan kabur intuisionistik bernilai interval adalah suatu ukuran untuk mengukur tingkat kekaburan atau tingkat ketidakjelasan dari suatu himpunan kabur intuisionistik bernilai interval.

(2) Misalkan suatu IVIFS $A=\left\{\left(x_{i},\left[u_{A}^{-}\left(x_{i}\right), u_{A}^{+}\left(x_{i}\right)\right],\left[v_{A}^{-}\left(x_{i}\right), v_{A}^{+}\left(x_{i}\right)\right]\right) \mid x_{i} \in X\right\}$ dan terbukti bahwa suatu ukuran entropi baru untuk IVIFS adalah $E(A)=\frac{1}{n} \sum_{i=1}^{n} \cos \frac{\left|u_{A}^{-}\left(x_{i}\right)-v_{A}^{-}\left(x_{i}\right)\right|+\left|u_{A}^{+}\left(x_{i}\right)-v_{A}^{+}\left(x_{i}\right)\right|}{2\left(2+\pi_{A}^{+}\left(x_{i}\right)+\pi_{A}^{-}\left(x_{i}\right)\right)} \pi$.

(3) Ukuran entropi $E(A)$ lebih efektif dan logis untuk mengukur tingkat kekaburan atau ketidakjelasan dari himpunan kabur intuisionis-tik bernilai interval ( $I V$ IFS) dibandingkan dengan ukuran entropi yang yang diperkenalkan oleh Ye $[?]$.

\section{Ucapan Terima kasih}

Penulis mengucapkan terima kasih kepada Bapak Prof Dr. I Made Arnawa, Bapak Dr. Jenizon, dan Ibu Monika Rianti Helmi, M.Si yang telah memberikan masukan dan saran sehingga makalah ini dapat diselesaikan dengan baik.

\section{Daftar Pustaka}

[1] Atanassov, K.T. 1986. Intuitionistic fuzzy sets. Fuzzy Sets and Systems. 20: $87-96$

[2] Atanassov, K. \& G. Gargov. 1989. Interval-valued intuitionistic fuzzy sets. Fuzzy Sets and Systems. 31: $343-349$

[3] Burillo, P. \& H. Bustince. 1996. Entropy on intuisionistik fuzzy sets and on interval-valued fuzzy sets. Fuzzy Sets and Systems. 78:305 - 316

[4] Liu, X.D.,S.H. Zhang, \& F.L. Xiong. 2005. Entropy and subsethood for general interval-valued intuitionistic fuzzy sets. Fuzzy Systems and Knowledge Discovery. 181: $4273-4286$

[5] Luca, A. de \& S. Termini. 1972. A definition of a nonprobabilistic entropy in the setting of fuzzy sets theory. Information and Computation. 20:301 - 312

[6] Szmidt, E. \& J. Kacprzyk. 2001. Entropy for intuitionistic fuzzy sets. Fuzzy Sets and Systems. 118: $467-477$

[7] Vlachos, I.K. \& G.D Sergiadis. 2007. Intuitionistic fuzzy informationaplications to pattern recognition. Pattern Recognition Letters. 28:197 - 206 
Ukuran Entropi Baru pada Himpunan Intuisionistik Bernilai Interval 281

[8] Wei, C.P. \& Y.Z. Zhang. 2015. Entropy measures for interval valued intuitionistic fuzzy sets and their application in group decision making. Information Sciences. 13: $1155-1168$

[9] Xu, Z. \& Da, Q.L. 2002. The uncertain OWA operator. Int. J. Intell. Syst. 17: $569-575$

[10] Ye, J. 2010. Multicriteria fuzzy decision-making method using entropy weightbased correlation coefficients of interval-valued intuitionistic fuzzy sets. Applied Mathematical Modelling. 34:3864 - 3870 